\title{
Continuing Professional Development (CPD) for pharmacists in three countries with developing health systems
}

\section{ABSTRACT \\ Introduction}

The role of pharmacists in healthcare is undergoing transformation throughout the world. The Continuing Professional Development (CPD) model has motivated the pharmacists in the developed countries to adopt lifelong learning. This is vital to improve competence and to optimize patient care. The study explores the existence and understanding of CPD model in Ghana, Pakistan as well as Trinidad and Tobago. It further explores the barriers faced in development of a CPD model and suggests probable policies to be implemented for building/improving such a model.

\section{Methods}

Audiotaped qualitative in-depth interviews were conducted with pharmacy stakeholders: academics, community pharmacists and regulatory professionals then transcribed and coded. A thematic analysis of the transcribed data led to the extraction of the main themes.

\section{Results}

The Findings showed a process of establishment of CPD for pharmacists in Ghana whereas in Pakistan and Trinidad and Tobago there was no CPD model for pharmacy practitioners.

\section{Conclusion}

The findings conclude the need for a realistic, relevant and mandatory program of CPD model in these countries.

\section{Keywords}

Continuing Professional Development (CPD), Continuing Education (CE), pharmacy practice, Pharmacy education, low and middle income countries.

\section{Conflict of interest}

The authors declare no conflict of interest.

\section{Disclosure statement}


None, no specific funding was available to undertake this study. The study is part of MSc research undertaken by the first author of this article.

\section{Introduction}

To improve medicines use and pharmacy practice in a country, pharmacists' professional roles need to be updated. This is in accordance with the public health and health system needs of the country. ${ }^{1}$ Also, to achieve good pharmacy practice, every system needs well-established guidelines and standards which also need to be practiced and continuously developed. ${ }^{2}$ In the current era, the professional 
learning needs of pharmacists must be established if pharmacists need to expand their scope of practice. $^{3}$

\section{$1.1 \quad$ CPD}

According to International Pharmaceutical Federation (FIP), Continuing Professional Development (CPD) is "the responsibility of individual pharmacists for systemic maintenance, development, and broadening of knowledge, skills, and attitudes, to ensure continuing competence as a professional, throughout their careers". ${ }^{2}$

In low- and middle-income countries (LMICs') there still exists a gap between the pharmacy education and training. Though the didactic teaching is done on pharmacotherapy in Pakistan but its direct application and training is scare at community pharmacies. Though we have started to see this in the hospital settings but still there is a need to implement structured training and internship programs in the area of hospital pharmacy.$^{4}$ One of the best interventions to strengthen pharmacy practice is to expose pharmacists to a lifelong learning experience which would ultimately lead towards an advancement in pharmacy practice. ${ }^{5}$ This could be done in the form of CPD. For this pharmacists who are practicing are required to be completely willing towards maintaining their skills, updating their knowledge and improve their practice standards. ${ }^{3}$ The pharmacy workforce also needs to be consistently trained and educated to provide high-quality pharmaceutical care to the patients. ${ }^{6}$

\subsection{Benefits of CPD}

The CPD model enables individuals to assess their knowledge gaps and to design their learning techniques. ${ }^{7} \mathrm{CPD}$ links learning with practice as it provides an opportunity to plan individual professional development strategy on the basis of one's knowledge gaps and practice needs. The CPD model helps in linking current practice to what is expected by the profession in terms of professional ability and conduct. $^{8}$

A CPD model is designed to ensure that pharmacy practitioners provide patient-centered care, apply evidence-based practice and boost quality and use health information technology. ${ }^{7}$

\subsection{The Status of CPD in High-income countries with well-developed healthcare systems}

Many pharmacy educational and regulatory organizations have conducted activities for the development of CPD in high income countries, the Pharmaceutical Society of Ireland carried out a study 
of CPD models in $2010^{9}$ while the FIP in 2014 recorded a wide variation in the development of implementing a framework for CPD globally. ${ }^{10}$

Table 1 presents an overview of the case studies depicting trends of CPD in high income while the Table 2 shows status of pharmacy education and development in some LMICs'.

\subsection{The status of Pharmacy Education and Practice in Pakistan, Ghana and Trinidad and Tobago}

Table 2 highlights the status of Pharmacy Education and Practice in Pakistan, Ghana and Trinidad and

Tobago. Some of this information provided in the table has been extracted from the Global report of International Pharmaceutical Federation ${ }^{10}$ on CPD in pharmacy.

\subsubsection{Pakistan}

Pakistan is a lower middle-income country with a total population of 220 million and is the world's sixth most populated nation. ${ }^{19}$ Many pharmacies in cities are being operated as per modern and international standards but this practice is limited to the main cities. Unfortunately, population among the rural areas and small towns remain deprived of access to quality pharmacists and pharmacies. A shortage of pharmacists has also been reported in the country. ${ }^{20}$ The government is still unable to meet the target set by the World Health Organization (WHO) which is 5 pharmacists per 10,000 persons population whereas the actual availability is 0.06 pharmacists per 10,000 persons population. ${ }^{21}$ In Pakistan, the pharmacy education system was upgraded to a five-year Pharm-D program in 200422 .Though pharmacotherapy was included in the curriculum however, deficiencies in health system makes it difficult for pharmacists to practice and provide optimal patient care at both hospital and at community pharmacies. ${ }^{20,23}$ The organizational and structural changes include mandatory presence of pharmacists at community pharmacies. The curriculum also needs continuous improvement by including patient counseling, patient centered practice and to help develop essential clinical skills to provide optimum pharmaceutical services to the population. ${ }^{24}$

The pharmacists in Pakistan are struggling in terms of unattractive salary packages, poor health and pharmacy support infrastructure and little acknowledgement of their role as a patient centered practitioner. ${ }^{21}$ According to a survey conducted in 2015 of pharmacists working in different fields, 
reluctance of pharmacists towards taking up their roles in retail pharmacies was observed as $85.42 \%$ of the respondents showed unwillingness to work as retail pharmacists. ${ }^{24}$

Though in recent years, published pharmaceutical policy and practice literature in Pakistan has increased manifold ${ }^{25}$, however patient oriented practice at community pharmacy level has not changed much. Pharmacists still need to assert their roles in terms of sole dispenser of medicines and to promote quality use of medicines. ${ }^{20,25,26 \text {, and } 27}$

\subsubsection{Ghana}

The Ghana has a population of 29.7 million and is a lower middle-income country. ${ }^{28}$ According to Pharmacy Council of Ghana there are 1759 pharmacies,2640 pharmacists with 1629 currently practicing. ${ }^{17}$ The pharmaceutical policy goals in Ghana are ensuring the quality of medicines, public access to essential medicines, efficient medical supply and rational use of pharmaceutical products. ${ }^{29}$ In Ghana, academia, industry, hospital, retail and regulatory practices are the domains of the pharmaceutical system. ${ }^{17}$

A study was conducted in 2008 in Ghana among the final year pharmacy students to analyze their perceptions regarding future opportunities and professional aspirations. The study highlighted that the pharmacists have a committed and goal-oriented attitude towards the profession. On the contrary lack of interest by the policymakers was indicated a reason for an underdeveloped pharmacy practice system in Ghana. ${ }^{30}$

According to the report released by the Pharmacy Council of Ghana (PCG) in association with the World Health Organization (WHO) and The European Union (EU), Continuing Professional Development (CPD) was considered compulsory for the pharmacists in Ghana. Multiple pharmacy practice Continuing Professional Development (CPD) courses were conducted in Ghana which included courses on the standard treatment procedures, safe use of medicines as well as drug management. ${ }^{17}$

\subsubsection{Trinidad and Tobago}

Trinidad and Tobago has a population of 1.33 million $^{31}$ and as per the statistics of 2012 there are 1050 registered pharmacists in the country. ${ }^{32}$ There are various ways in which the pharmacy curriculum in Trinidad and Tobago can be improved which may include incorporation of technology courses or introducing clinical experience throughout the Bachelors of Pharmacy programme. ${ }^{33}$ 
Alongside many other countries, Trinidad and Tobago's health system is following a path towards patient-centered practice and is facing numerous challenges to improve pharmacist's roles and responsibilities. ${ }^{33}$ Trinidad and Tobago has started building reforms in their current curriculum and to enhance the existing practice settings. ${ }^{31}$ It is compulsory for a pharmacy graduate to complete an internship of six months to get registered with the Pharmacy Board of Trinidad and Tobago. ${ }^{34}$

\subsection{Aims and Objectives}

This study intends to explore the stakeholders' views, perceptions and practices regarding the Continuing Professional Development (CPD) in Pakistan, Ghana and Trinidad and Tobago. The stakeholders include academic, pharmacy practitioners and regulators for pharmacy profession. The work has the following objectives

- To understand the stakeholders' views regarding Continuing Professional Development (CPD) and Continuing Education (CE) in Pakistan, Ghana and Trinidad and Tobago.

- To explore facilitators, barriers, opportunities and recommendations in developing a CPD model for pharmacy practitioners in Pakistan, Ghana and Trinidad and Tobago.

- To explore future expectations related to CPD for the pharmacists in these countries.

\section{Methods}

The qualitative research methods was adopted to conduct this research. A qualitative research method is designed to incorporate views, experiences, behaviours, and opinions of pharmacy oriented stakeholders. ${ }^{35}$

A general inductive study was conducted which involved semi structured interviews to explore perception of stakeholders on the status of Continuing Professional Development (CPD) in countries with developing health systems mainly including low and middle-income countries. To gather views and perceptions of various stakeholders a semi structured interview guide was designed which was finalized after a pilot interview and then further interviews were conducted. In this study the data analysis led to the extraction of themes which helped in building a model.

\subsection{Development of semi structured interview guide}

Most questions designed were open ended. ${ }^{36}$ The semi structured interview guide was divided into the following themes: 
- The concept of CPD

- The current status of CPD in the particular country

- The opinion on the effectiveness of the CPD model, producing CPD ready graduates and interest of pharmacy practitioners towards following of the CPD model

- Ideas on the key components of building this model for their particular country

- Solutions suggested to the barriers identified in the CPD

- Future expectations

\subsection{Recruitment of participants}

A purposive sampling technique was followed. Overall 70 stakeholders were approached, out of which, 12 agreed to participate. A total of 12 telephonic interviews were conducted, which were audiotaped and then transcribed. Table 3 shows the number of participants approached and responded for this study in each country.

The participants were selected from three countries which are Ghana, Pakistan and Trinidad \& Tobago. The reason behind selecting these countries is that all are Commonwealth nations and range from a spectrum of high to low- and middle-income countries. Pakistan and Ghana are lower middle-income countries, while Trinidad and Tobago is a middle-high income country. ${ }^{19}$ Although Trinidad and Tobago is a high income country with per capita income of $17,265.465$ US $\${ }^{19}$ however it's a country with a developing health system ${ }^{31}$; hence it's been included in this study. The participants were selected from regulatory authorities, academia and the community pharmacy setup.

\subsection{Transcription, Coding and Data Analysis}

The interviews conducted were audiotaped and then transcribed. Coding was done once all research interviews were transcribed verbatim and checked. ${ }^{37} \mathrm{~A}$ qualitative research software by the name of NVivo12 was used to manage the coding of transcriptions and data analysis (NVivo 12for coding).Coding helps the researcher to see the world from the informants' perspective as it enables them to identify the issues which are highlighted in the participants' narratives ${ }^{37 .}$ 


\subsection{Ethical Considerations}

Ethical clearance for conducting this study was received from the University of Huddersfield Ethics Committee (Reference number: SAS-SREIC 14.5.19-1).

\section{Results}

As the purpose of the research was to explore pharmacy stakeholders' views and perceptions regarding the Continuing Professional Development (CPD) model all participants selected were pharmacists by profession belonging to different areas of practice. Table 4 outlines participants' profiles from Pakistan, Ghana and Trinidad and Tobago.

\section{Understanding of CPD and CE in global practice}

All participants were aware of the terms "Continuing Professional Development (CPD) and Continuing Education (CE) however their understanding of these terms were different. During the participant recruitment process, responses of a few pharmacists from Pakistan showed that they were not aware of these terms. However, in Ghana and Trinidad and Tobago participants have some understanding of these terms. One of the participants from Ghana revealed: "I think that the concept of CPD for us is a bit new in this part of the world."(R3)

The process of CPD was well defined by a regulator in the Trinidad and Tobago: "It's more in the center and it involves reflecting on what a person has to think about what their needs are and then they identify the plan for it. And then the learning material, then they need to implement it, so it's more of an individual need based learning."(R4)

A senior official in the Ministry of Health, Pakistan stated his understanding of CPD in the following words: "I think on professional level brushing up your knowledge between new technology, new techniques, new knowledge, or continue to upgrade the knowledge, skills and competencies to go up is CPD."(R1)

Our findings showed that the participants' concept regarding CPD reflects that it is necessary for pharmacists to upgrade their knowledge during their practice.

Participants from Ghana briefly described how Continuing Professional Development (CPD) is carried out in Ghana and what does it involve. A community pharmacist from Ghana explained in detail how 
Continuing Professional Development (CPD) events are currently being organized and what do they involve:

"What happens is that CPD events are usually organized at a venue where you usually go, you need to book in advance that what CPD course you want to participate through a moderator. There's a moderator there to do the CPD. Usually there's a resource person too there. And after that, even sometimes we even been bring into groups first to discuss this within groups, solve problems that we've learned and to implement the things that we've learned there before we leave. And then usually, certificates are issued out to participants of the CPD."(CP2)

The participant working with the pharmacy council of Ghana briefly explained how accreditation system for pharmacists' Continuing Professional Development (CPD) actually works:

"So, by the end of the year, you have a number of points that you are supposed to hit via the institution that are accredited to all past CPDs. So, what happens is that those institutions, they get accreditation from the pharmacy council."(R3)

The community pharmacist from Ghana also gave information about how Continuing Professional Development (CPD) courses are offered:

"We have so many different categories of CPD programs for different pharmacists who practice in different areas. For example, we have separate CPDs for people who are within the regulatory space. We have separate CPDs for people who work within the clinical setting. We have CPDs for people who work in the community space."(CP2)

\section{What is the difference between CPD and CE?}

One of the academics from Ghana said that CE is not necessarily related to your profession but CPD is purely related to the profession: "Continuing Education could be anything you want to learn and it may or may not be related to your profession, whereas Continuing Professional Development have to do mainly with whatever profession you are in."(A2)

A community pharmacist from Trinidad and Tobago gave a detailed opinion regarding how CPD is different from the CE: "CPD would be like a process to enhance personal need based skills, knowledge 
and experience formally and informally whereas continuous education is more like attending formal programs and like courses designed to educate, augment and improve your skillset." (CP4)

\section{Current status of CPD in Ghana, Pakistan and Trinidad and Tobago.}

A pharmacist from Ghana informed us that the CPD is compulsory in Ghana and stated this in the following manner: "At the moment, so working as a practitioner in pharmacy, you've got to undertake $C P D$ every year and there's a minimum number of credits you need to acquire."(A2)

An academic from Pakistan told us that there is no compulsory CPD program and stated the following view:" The CPD should have been compulsory but on floor practically, there is nothing like compulsory CPD programs."(A1)

Informants from Trinidad and Tobago revealed that no CPD is in practice: "It is missing at the government side. I've never seen any such program being, you know a pharmacist in Trinidad and Tobago."(A4)

\section{Barriers towards the development of CPD}

Our research participants from Ghana informed us about the barriers they face in completing their CPD hours. The informants from Pakistan and Trinidad and Tobago also highlighted the existing barriers due to which there is no established CPD system in these countries.

\section{1-Time and Finances}

Pharmacists from Ghana suggested a system for taking up online CPD courses to complete their points as they considered it very time consuming to go and attend the event:" I have a very tight schedule, so if I need to be at a confined place within a certain time, it's going to be tough. But if it is an online program, maybe when I'm closed after 10:00 p.m. and I'm relaxed at home, I could just start- I could just log on and start doing the training at my own time. "(CP2)

"You have to look at the hours that pharmacists work with. You have to look at the bosses if they would give them time off to attend to the lectures."(CP3)

Similarly another pharmacist from Trinidad and Tobago highlighted finance as a major issue in the implementation of a CPD model "One of the major hurdles is financial constraints, off course a lot of financial resources are required to bring such a model into practice, our government seems to be unable to spare funds to take up such a big project for us pharmacists."(CP4) 


\section{2-System Constraints}

A few participants completely blamed the national pharmacy regulatory system for not implementing CPD model for pharmacy practitioners in their regions. A pharmacist from Trinidad and Tobago revealed the inefficiency of the local Pharmacy Regulatory Authority: "We have a lot of new projects proposals, we always have foreigners who want to come with these fantastic ideas, but it never gets over the floor because there's no implementation and there's nobody monitoring it."(CP3)

A pharmacist from Pakistan pointed out the negligence of national pharmacy council for having no CPD for pharmacy practitioners: "Wherever the pharmacist is working, requirement of their job should be mandatory requirement of CPD, and this can be implied only if the system will be properly structured and strict then everybody will have to do CPD."(R3)

\section{3-The Attitude of pharmacists towards participating in CPD}

The participants from Ghana shared their experiences regarding the attitude of pharmacists towards the compulsory intervention of CPD. The participants from Pakistan and Trinidad and Tobago also shared their thoughts on the expected behavior of their colleagues towards following a CPD model. A community pharmacist from Ghana shared his thoughts on pharmacists' interest towards CPD activities: "I think most people participate in it because they really want to be eligible to practice the following year. Not really their motivation that they are going to learn new things."(CP2)

One of the pharmacy regulators from Pakistan emphasized on making CPD mandatory for pharmacists in Pakistan to develop their interest in attending CPD events: "I think the majority people may not actually be able to relate unless it was somehow mandatory in getting their registrations renewed if it's not mandatory then there could be rather smaller proportion of people who would be really keen on updating themselves, so there has to be some kind of incentive or some kind of scheme to motivate pharmacists to come towards CPD."(R1)

\section{Facilitators in developing/improving a CPD model for pharmacy practitioners in Pakistan, Ghana and Trinidad and Tobago}

According to our informants the national pharmacy regulatory bodies, academics and Commonwealth Pharmacists Association (CPA) can be the key facilitators in developing/improving a Continuing Professional Development (CPD) in Pakistan, Ghana and Trinidad and Tobago. 


\section{1-The role of Pharmacy Professional Regulatory Bodies}

The stakeholders which were interviewed gave opinions on how Pharmacy Professional regulatory bodies can facilitate the implementation of CPD model in pharmacy practice. For example a participant from Pakistan highlighted his point in the following manner: "I think it's primarily within the realm of the pharmacy council to start a CPD program and make it mandatory."(R1)

A pharmacist from Trinidad and Tobago also shared her views regarding the role of pharmacy professional regulatory bodies: "There is a dire need to make CPD compulsory for licensure so a policy has to be made and in terms of managing resources and tools that facilitate exchange teaching and learning experience. All this can only be done if the Pharmaceutical Society will act responsible."(R4)

\section{2-The role of the Academics}

The participants during their interviews highlighted the role academics can play in the development of a CPD model in countries with developing health care system. A pharmacy stakeholder from Pakistan added that if the concerned pharmacy council makes practice of CPD mandatory then there is also an expectation from the academics to step forward and design a suitable CPD program for the pharmacists on ground. He presented his thoughts in the following words: "Well I think good universities in the region do have the capacity and the capability to actually undertake this kind of work to develop a CPD model as per the requirements, given if it becomes compulsory."(R1)

Participants also proposed to adopt an approach to assimilate concept of CPD in the pharmacy curriculum so that graduates can be well aware about the CPD practice when starting off their careers.

\section{3-The role of The Commonwealth Pharmacist Association (CPA)}

Our research informants considered Commonwealth Pharmacists Association (CPA) as a major facilitator if a CPD model has to be implemented to strengthen pharmacy practice in low and middle income countries

A pharmacist from Pakistan gave valuable suggestions and ideas regarding the role of Commonwealth Pharmacists Association (CPA) for the development of a CPD model for pharmacy practitioners in Pakistan: "CPA can involve the national pharmacist association, national statutory and ministry of national health, all three to involve initially and CPA can give them a model and content of the CPD, 
then definitely our regulators will conduct the CPD once they have support because CPA as is developing such CPD model for other countries, so it can bring the best practice in this country by bringing success stories of those countries."(R2)

\section{Key components needed to establish/improve a CPD model in Pakistan, Ghana and Trinidad and}

\section{Tobago}

The stakeholders involved delivered a variety of opinions regarding what is needed to build a CPD model as per their understanding. A participant who is professionally an academic pharmacist from Pakistan suggested the following: "I think the key components would be, number one, the attachment of the requirement of registration or the license validity to CPD courses. Then the priority should be given to what is the need of the country and the topics should relate to somehow feeding to the improvement of the health indicators of the region."(A1)

Another valuable opinion by one of the pharmacists from Pakistan regarding the key components needed to build a Continuing Professional Development (CPD) model was: "I think the technical aspects, the communication and patient counselling aspects, the technology and the leadership with the management aspects, I think you can't put them all together into one program."(R1)

A pharmacist from Trinidad and Tobago shared her views in a detailed manner highlighting that what is the key to develop a model for CPD for the pharmacists:

"Well I think you would need to have, first of all, a mandate, and you need an association as well to take on that mandates like stakeholders, that would be the ministry and anybody that create bills and adjust recommendations because you have to have a legislative framework to start with. You also need to have international partner so those credits are recognized. Also partnering with local universities and keeping a representative in a space where they can get information from people what their needs are. So those are key components, a way in which you can engage stakeholders and get new recognition and a legislative frameworks."(R4)

\section{Future of CPD in Pakistan, Ghana and Trinidad and Tobago}

The participants revealed that where do they see CPD in pharmacy practice in Ghana, Pakistan and Trinidad and Tobago in five years' time and all participants shared that they see positive future 
development regarding CPD in these countries. An academic pharmacist from Ghana expects CPD to be much more developed in pharmacy practice:

"In the next five years I expect to see a more streamlined CPD model where it's easier to assess the CPD courses, and we move more towards online CPD programs where it's readily accessible rather than physical seminars."(A2)

A pharmacist working with the pharmacy council of Pakistan shared his optimistic views regarding the future of CPD in pharmacy practice: 'Well if you say in five years' time the whole paradigm shifts, yes, that could be possible here in this country, these are very resilient people and they are ready to change. I then hope that the Pharmacy Council will make sure that every pharmacist who wants to remain a licensed pharmacist will have CPD."(R2)

A pharmacy stakeholder who is an official in pharmacy council of Trinidad and Tobago briefly described how she foresees the CPD practice in pharmacy in her country:

"I think a CPD model would be developed by then because we're getting more and more calls from institutions that want their pharmacists to be more advanced in so now they are interested in more structure and advanced practice, it's going to be slower but I think in a public sector, we will have CPD and we'll see more modules being offered or being requested from teaching institutions."(R4)

\section{Discussion}

According to the results obtained CPD is a self-driven assessment taken by a pharmacist to identify their learning needs and to take necessary action to improve and implement their knowledge which was further supported by a study explaining that the Continuing Professional Development (CPD) enables a pharmacist to assess their learning gaps, to devise a plan, execute their planned strategy and then evaluate the success of their implemented intervention. ${ }^{38}$

Our study findings showed that the participants were clear on this that Continuing Professional Development (CPD) is to maintain professional competence. It is mandatory for pharmacists in Ghana to attend CPD events to renew their registration whereas the pharmacists in Pakistan and Trinidad and Tobago just have to pay a fee for the renewal of their licenses and it is not compulsory for them to carry out CPD or CE as there is no such established system in the country. ${ }^{16,17}$ and 18 
Pharmacists from Ghana briefly described that pharmacists book their CPD courses which are arranged at a venue by a moderator and then they have to go attend them and this involve lectures and discussions and then there is a group discussion that how can this all be implemented. By the end, certificates are awarded and when a pharmacist logs in at the venue their CPD is recorded and they gain points. These results partially satisfy the concept of CPD as a cyclic process of learning which is self-initiated and covers the components of reflection, planning, learning, evaluating, implementing and documenting. ${ }^{5}$

The participants from Pakistan suggested that the development of a CPD model should be of joint responsibility of the National Ministry of Health, Pharmacy Council of Pakistan (PCP) and the Pakistan Pharmacists Association (PPA) also highlighted in the literature. ${ }^{16,39}$

The participants also expected that the model for CPD for pharmacy practitioners should be carefully designed in order to motivate and facilitate the pharmacists. Non-availability of financial resources was also a significant barrier in not having an established CPD program by the stakeholders. The financial barrier in the development and implementation of advanced pharmacy practice techniques and interventions in the low and middle-income countries is also indicated as a key barrier, also highlighted in a systematic review of literature. ${ }^{40}$

According to our research findings there is a desperate need for designing and implementing of a CPD for pharmacists but the responsible authorities do not have sufficient funds to do so. The pharmacy councils and boards do not have enough money as this development requires finance. It needs money to hire experts who will design a CPD model as per the country needs then the next step is perhaps training sessions and training of the trainers. The participants suggested that it is the duty of the pharmacy council or pharmacy boards to set-up CPD in their countries. The national pharmacy associations need to work hard to develop the pharmacy practice as per the global standards. ${ }^{41,42}$ Our findings suggest that the pharmacy councils in respective countries should approach academics, and should work and collaborate with them to organize joint events of CPD at the universities. The role of academics to promote CPD is also supported from the literature as it was stated that pharmacy academia can add their knowledge in updating the current curriculum and to train the students. ${ }^{43}$ 
The CPD model designed should be able to cover the aspects involved regarding day to day pharmacy practice. Along with relevance to the present need of the health sector the CPD model should also address the technicalities involved in administering patient care as well as patient-pharmacist communication. ${ }^{5}$

In nutshell an exemplary CPD model should include the following components:

1. Managerial and leadership skills

2. Pharmacotherapy and pharmacy management CPD courses

3. Updated knowledge on diseases and public health

4. Local needs of the country and the regions

5. Support from pharmacists' employers

6. Links with the International Organizations

7. Efficiency in renewal and registration of the pharmacists

The below model (Figure 1) highlights these components.

Figure 1 highlights the factors which contribute towards advancement in pharmacy practice and improvement in public health. CPD is an important factor in development of pharmacy practice as it involves training of pharmacists and enhances their skill set. The figure also indicates necessary components to be kept in consideration while designing a CPD model.

\subsection{Limitations of the study}

Recruiting suitable key stakeholders was a challenge in the study. The researcher spent a number of months and great deal of time and 70 participants were approached, however, only 12 participants gave consent to participate in the study. Though hospital pharmacy is an important setup however the study does not specifically focus on the hospital setting. The focus was primarily on primary care and the CPD and CE system in community pharmacy practice. Nevertheless, the present study provides useful information to build policy changes for CPD and pharmacists.

Further studies could include hospital pharmacy and how a CPD model could be useful in this context. However despite the limitation of not having a large number of respondents in entire countries, the data set obtained from this study is contextually rich and the findings can be used to build the questions for a 
quantitative survey, as well as policy recommendations. The findings and key results from this study are also helpful to build the different aspects of a generic CPD model. .

The countries chosen Pakistan, Ghana and Trinidad and Tobago are at a different level of development in pharmacy and health systems. This perhaps also highlights the similarities, differences and problems in many other low- and middle-income countries which are of similar socio-economic status. ${ }^{44}$ The results from this study may be generalized in other settings as the issues and findings may not be very different from the other countries with the similar socio-economic and health status.

\section{Conclusion}

The views and perceptions of key stakeholders were mapped and the results implied that the inefficiency of the regulatory councils as one of the main barriers in developing a Continuing Professional Development (CPD) model for the pharmacists in Pakistan, Ghana and Trinidad and Tobago. In order to improve the pharmacy practice in the developing health systems, it is crucial that a mandatory CPD model is established and enforced.

A concordant and joint effort by policymakers, academics and pharmacy practitioners is recommended to develop CPD in the surveyed countries. Ongoing research on the topic would indeed be useful to strengthen the process and to structure an informed CPD model.

\section{Acknowledgments}

We would like to say thanks to Dr Syed Shahzad Hasan for his help in initial ethics application.

\section{References}

1- Whalley BJ. Pharmacy and the Pharmacist. In: Whalley BJ, eds. Foundation in Pharmacy Practice. Pharmaceutical Press United Kingdom; 2008:01-04.

2- Joint FIP/WHO guidelines on good pharmacy practice: standards for quality of pharmacy services. Published 2011. Accessed 23 November 2020. Retrieved from https://www.fip.org/file/1476.

3- Schindel T, Yuksel N, Breault R,et al. Pharmacists' learning needs in the era of expanding scopes of practice: Evolving practices and changing needs. Res.SocialAdm.Pharm. 2019;15(4):448-458. doi:10.1016/j.sapharm.2018.06.013 
4- Babar Z, Scahill S, Akhlaq M.et al. A bibliometric review of pharmacy education literature in the context of low- to middle-income countries. Curr Pharm Teach Learn. 2013;5(3):218-232.

doi:10.1016/j.cptl.2013.01.001

5- Zarembski D G \& Rouse M.J. Continuing Professional Development for Clinical Pharmacists.In Z. Babar,eds. Encyclopedia of Pharmacy Practice and Clinical Pharmacy.Elsevier;2019:66-78. doi: https://doi.org/10.1016/B978-0-12-812735-3.00112-6

6- Anderson C, Bates I, Beck D et al. The WHO UNESCO FIP Pharmacy Education Taskforce. Hum Resour Health. 2009;7(1). doi:10.1186/1478-4491-7-45.

7-Institute of Medicine. Redesigning Continuing Education in the Health Professions. Washington, DC: The National Academies Press; 2010:58-92.Accessed 24 November 2020.Retrieved from http://www.books-google.co.uk.

8-Hancox D. Making the move from continuing education to continuing professional development.Pharm.J.2003.Accessed 23 November 2020.Retrieved from https://www.pharmaceuticaljournal.com/pj-online-cpd-making-the-move-from-continuing-education-to-continuing-professionaldevelopment/20005771.article?firstPass=false.

9- Review of International CPD Models:The Pharmaceutical Society of Ireland. Published 2010.Accesed

24November2020.http://www.thepsi.ie/Libraries/Education/PSI_International_Review_of_CPD_Models. sflb.ashx..

10-Continuing Professional Development/Continuing Education in Pharmacy: Global Report. Published 2014. Accessed 24 November 2020.Retrieved from www.fip.org.

11-Australian Pharmacy Council. Accessed 24 November 2020. Retrieved from https://www.pharmacycouncil.org.au/.

12--The Canadian Council on Continuing Education in Pharmacy.Accessed 24 November 2020 Retrieved from. https://www.cccep.ca/ 13- Continuing Professional Development. Accreditation Council for Pharmacy Education. Accessed 24 November 2020.Retrieved from https://www.acpe-accredit.org/continuing-professional-developmentold/. 
14-Pharmacy Council of New Zealand. Accessed 24 November 2020.Retrieved from https://www.pharmacycouncil.org.nz/.

15-Council on Pharmacists' Crendentials..Published 2013.Accessed 25 November 2020. Retrieved from http://cpc-j.org/english/

16-Pharmacy Council of Pakistan. Accessed 25 November 2020.Retrieved from https://www.pharmacycouncil.org.pk/..

17-Pharmacy Council of Ghana. Accessed 25 November 2020 .Retrieved from http://www.pcghana.org. 18-Pharmacy Board of Trinidad and Tobago. Accessed 25 November 2020. Retrieved from http://www.health.gov.tt/.

19- Low \& Middle income|Data.World Bank Group. Accessed 24 November 2020.Retrieved from http://www.worldbank.org.Published 2019.

20-Atif M,Ahmad M,Saleem,et al. Pharmaceutical Policy in Pakistan. In Z Babar,eds.Pharmaceutical Policy in Countries with Developing Healthcare Systems (pp. 25-44). Cham: Springer International Publishing;2017. doi:https://doi.org/10.1007/978-3-319-51673-8_3

21- Malik I, Ikram H, Rafiq S. 71st anniversary of pharmacy profession in Pakistan: Why pharmacists' are still flying under the radar? Res Social Adm Pharm. 2019; 15(12):1495-1496.

doi:10.1016/j.sapharm.2019.09.060

22- Hussain A \& Jamshed S. Pharmacy Practice in Pakistan. Pharmacy Practice in Developing Countries. 2016:97-115. doi:10.1016/b978-0-12-801714-2.00006-x

23-Hashmi F, Hassali M, Saleem F,et al. M. A qualitative study exploring perceptions of policymakers about community pharmacy practice and extended pharmacy services in Lahore, Pakistan. J Pharm Health Serv Res. 2018;9(1):71-73. doi:10.1111/jphs.12216

24-Khan S, Qayum M,Sadozai S. Challenges in the shifting role of pharmacists in Pakistan. Pharmaceutical Care and Research. 2016;16(1):19-24. doi:10.5428/pcar20160106 25-Malik I, Atif M, Scahill S, et al. Pharmacy practice and policy research in Pakistan: A review of literature between 2014-2019. eds Babar, Z-U-D Global Pharmaceutical Policy. Palgrave Macmillan; 2020. ISBN 978-981-15-2723-4 https://www.palgrave.com/gp/book/9789811527234 
26- Babar, Z. Pharmacy education and practice in Pakistan. Am J Pharm Educ.2005; 69:2-3.Accessed 24

November2020.https://www.researchgate.net/publication/292390374_Pharmacy_education_and_practi ce_in_Pakistan_2.

27- Babar Z. Pakistan's National University of Pharmaceutical Sciences. Am J Pharm Educ. 2006; 70(5):123.Accessed 20 November 2020.

https://www.ncbi.nlm.nih.gov/pmc/articles/PMC1637010/citedby/

28- World Bank Group.Ghana/Data.Published 2019.Accessed 24 November 2020.

http://www.worldbank.org

29- Ghana national drug policy. Retrieved from https://www.moh.gov.gh/wp-

content/uploads/2016/02/Ghana-National-Drug-Policy-2nd-edition.pdf.Published 2004.Accessed 10 November 2020. https://www.who.int/selection_medicines/country_lists/gha_NDP_2nd_Ed.pdf. 30- Seiter A, Gyansa-Lutterodt M. The Pharmaceutical Sector in Ghana. 2009. doi:10.1596/2811730Owusu-Daaku F, Smith F, Shah R. Addressing the workforce crisis: the professional aspirations of pharmacy students in Ghana. Pharmacy World \& Science. 2008;30(5):577-583. doi:10.1007/s11096008-9214-7

31-Dhingra S, Maharaj S, Extavour R, et al. Pharmaceutical Policy in Trinidad and Tobago In Z Babar,eds. Pharmaceutical Policy in Countries with Developing Healthcare Systems.Springer; 2017:349-363. doi:10.1007/978-3-319-51673-8_17

32-Yearwood,A..Pharmaceutical Country Profile: Trinidad and Tobago. Published 2013.Accessed 09 November 2020.https://www.who.int/medicines/areas/coordination/PSCP_TRT_en.pdf?ua=1.

33 Ramrekha C, Ramkhelawan A, Singh R et al. Pharmacy Education in Trinidad and Tobago. Indian.J.Pharm.Educ. 2015;49(3):168-173. doi:10.5530/ijper.49.3.1

34-Maharaj S, Balroop A, Ali A et al. Bachelor of pharmacy graduates' perceptions of the pharmacy administration curriculum in Trinidad and Tobago. Curr Pharm Teach Learn. 2020;12(5):558-563. doi:10.1016/j.cptl.2020.01.015 
35- Herrera, H.(2019).Qualitative Methods in Pharmacy Practice Research.In

Z.Babar,eds,Encyclopedia of Pharmacy Practice and Clinical Pharmacy(pp. 29-38). Elsevier,2019.doi: https://doi.org/10.1016/B978-0-12-812735-3.00604-X

36-Rosenthal M. Qualitative research methods: Why, when, and how to conduct interviews and focus groups in pharmacy research. Curr Pharm Teach Learn.2016; 8(4):509-516.

doi:10.1016/j.cptl.2016.03.021

37- Sutton J, Austin Z. Qualitative Research: Data Collection, Analysis, and Management. Can J Hosp Pharm. 2015;68(3). doi:10.4212/cjhp.v68i3.1456

38-Driesen A, Verbeke K, Simoens S, et al. International Trends in Lifelong Learning for Pharmacists. Am J Pharm Educ. 2007;71(3):52. doi:10.5688/aj710352

39- Pakistan Pharmacists Association. Accessed 24 November 2020. http://ppapak.org.pk 40- Rasheed H, Izham M, Ibrahim M,et al. Evidence-Based Pharmacy Practice Research in Low- and Middle-Income Countries: Issues, Challenges and Synthesis. In Z.Babar, eds. Encyclopedia of Pharmacy Practice and Clinical Pharmacy.Elsevier ;2019:Volume 2:94113.doi:https://doi.org/10.1016/B978-0-128-12735-3/00145-X

41- Donyai P, Herbert R, Denicolo P, et al. British pharmacy professionals' beliefs and participation in continuing professional development: a review of the literature. J.Pharm.Pract. 2011;19(5):290-317. doi:10.1111/j.2042-7174.2011.00128.x

42- Babar Z, Jamshed S. Social pharmacy strengthening clinical pharmacy: why pharmaceutical policy research is needed in Pakistan?. Pharm World Sci.2008:30,617-619. https://doiorg.libaccess.hud.ac.uk/10.1007/s11096-008-9246-z 43-McLaughlin J, Dean M, Mumper R, et al. A Roadmap for Educational Research in Pharmacy. Am J Pharm Educ. 2013;77(10):218. doi:10.5688/ajpe7710218

44- Håkonsen H, Emmerick I \& Babar Z. Introduction. In Z.Babar,eds. Pharmaceutical Policy in Countries with Developing Healthcare Systems (pp. 1-9). Cham: Springer International Publishing;2017 doi:https://doi.org/10.1007/978-3-319-51673-8_17 